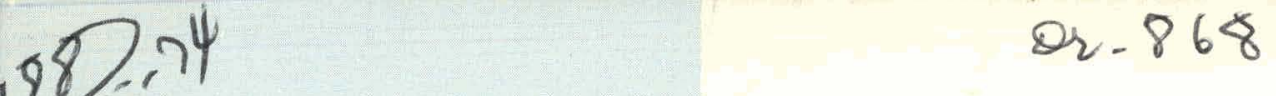

\title{
DYNAMIC GAMMA ATTENUATION DENSITY MEASUREMENTS
}

T.C. Piper

\section{Aerojet nuclear Company}

NATIONAL REACTOR TESTING STATION

Idaho Falls, Idaho - 83401

\section{MASTER}

DATE PUBLISHED-MAY 1974

\section{U. S. ATOMIC ENERGY COMMISSION}

IDAHO OPERATIONS OFFICE UNDER CONTRACT AT(1O-1)-1375 


\section{DISCLAIMER}

This report was prepared as an account of work sponsored by an agency of the United States Government. Neither the United States Government nor any agency Thereof, nor any of their employees, makes any warranty, express or implied, or assumes any legal liability or responsibility for the accuracy, completeness, or usefulness of any information, apparatus, product, or process disclosed, or represents that its use would not infringe privately owned rights. Reference herein to any specific commercial product, process, or service by trade name, trademark, manufacturer, or otherwise does not necessarily constitute or imply its endorsement, recommendation, or favoring by the United States Government or any agency thereof. The views and opinions of authors expressed herein do not necessarily state or reflect those of the United States Government or any agency thereof. 


\section{DISCLAIMER}

Portions of this document may be illegible in electronic image products. Images are produced from the best available original document. 


\section{DISCLAIMER}

This report was prepared as an account of work sponsored by an agency of the United States Government. Neither the United States Government nor any agency Thereof, nor any of their employees, makes any warranty, express or implied, or assumes any legal liability or responsibility for the accuracy, completeness, or usefulness of any information, apparatus, product, or process disclosed, or represents that its use would not infringe privately owned rights. Reference herein to any specific commercial product, process, or service by trade name, trademark, manufacturer, or otherwise does not necessarily constitute or imply its endorsement, recommendation, or favoring by the United States Government or any agency thereof. The views and opinions of authors expressed herein do not necessarily state or reflect those of the United States Government or any agency thereof. 


\section{DISCLAIMER}

Portions of this document may be illegible in electronic image products. Images are produced from the best available original document. 
Printed in the United States of America Available from

National Technical Information Service

U. S. Department of Commerce

5285 Port Royal Road

Springfield, Virginia 22151

Price: Printed Copy $\$ 4.00$; Microfiche $\$ 0.95$

\section{LEGAL NOTICE}

This report was prepared as an account of work sponsored by the United States Government. Ne ither the United States nor the United States Atomic Energy Commission, nor any of their employees, nor any of their contractors, subcontractors, or their employees, makes any warranty, express or implied, or assumes any legal liability or responsibility for the accuracy, completeness or usefulness of any information, apparatus, product or process disclosed, or represents that its use would not infringe privately owned rights. 


\title{
DYNAMIC GAMMA ATTENUATION DENSITY \\ MEASUREMENTS
}

\author{
by
}

T. C. Piper

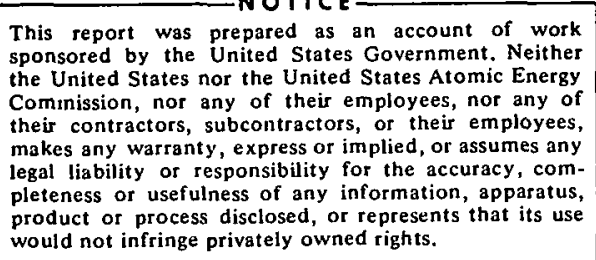
would not infringe privately owned rights.

\section{AEROJET NUCLEAR COMPANY}

Date Published - May 1974

\section{PREPARED FOR THE U. S. ATOMIC ENERGY COMMISSION \\ IDAHO OPERATIONS OFFICE \\ UNDER CONTRACT NO. AT(10-1)-1375}




\section{ACKNOWLEDGMENTS}

The author wishes to thank those who have contributed to the information containcd in this report:

H. R. Beveraux for originally pointing out the success of others utilizing gamma attenuation for density measurement, and for his help in early method evaluations.

N. Wilde for his help in clarifying the statements of Sections $\mathrm{H}-3$ and -4.1 .

B. V. Thornton for bringing the dynode memory effect of Section II-4.44 to my attention.

J. F. Turpin and H. T. Brown for their competence in producing the circuitry used in various tests.

The Semiscale Program for their understanding and funding of the early work in this fỉeld. 


\begin{abstract}
The considerations important in making density measurements, in small response time, by gamma attenuation measurement are enumerated and commented upon. A formula for the gamma source strength versus various parameters is obtained. Errors due to filtering, "streaming", wall adherence, and detector peculiarities are discussed.
\end{abstract}


ACKNOWLEDGMENTS $\ldots \ldots \ldots \ldots \ldots \ldots \ldots$ ii

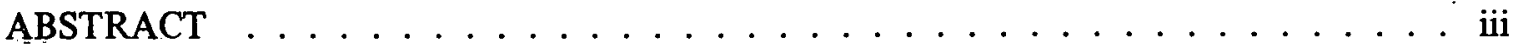

I. INTRODUCTION $\ldots \ldots \ldots \ldots \ldots \ldots$

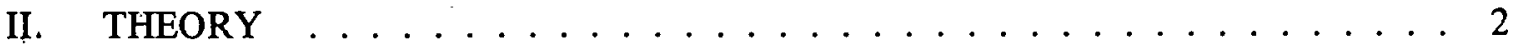

1. GENERAL ................... 2

2. COLLIMATION AND/OR ENERGY ANALYZATION . . . . . . . 3

3. MEASUREMENT RESPONSE TIME $\ldots \ldots \ldots \ldots \ldots \ldots$

4. $\quad$ ERRORS $\ldots \ldots \ldots \ldots \ldots \ldots \ldots \ldots \ldots \ldots \ldots \ldots \ldots \ldots \ldots$

4.1 Logging and Data Bias . . . . . . . . . . . . . 7

4.2 Gamma "Streaming" or Nonhomogeneity Error . . . . . . . . 8

4.3 Wall Adherence Error (Annular Flow) . . . . . . . . . . . 11

4.4 Scintillator and Photomultiplier Related Errors . . . . . . . . . 13

4.5 Electronics Errors . . . . . . . . . . . . . . . . . . . 14

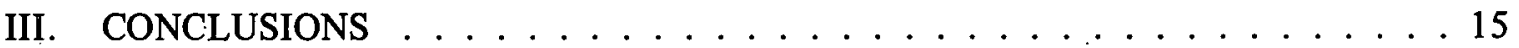

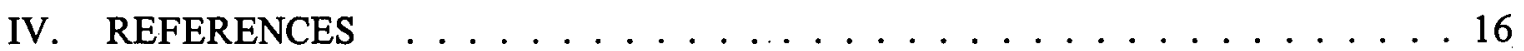

\section{FIGURES}

1. Variation of $\mathrm{R}$ during typical dynamic density measurement $\ldots \ldots \ldots \ldots$

2. Typicai piping gamma attenuation density measurement $\ldots \ldots \ldots$

3. Splitting of the gamma beam path into parts $\ldots \ldots \ldots \ldots$

TABLE

I. Values of $\mathrm{f}(\mathrm{K})$ Versus $\mathrm{K} \ldots \ldots \ldots \ldots \ldots$ 


\section{INTRODUCTION}

In instances where a density measurement is required of a single-phase fluid, at rest or in quasi steady state motion, a variety of measurement methods is available ${ }^{[1]}$. But, when the fluid is of more than one phase or in rapid or accelerated motion and when a density measurement is most likely to be needed, few measurement methods are adaptable. This report has been written to show how accurate density measurements can be made by gamma attenuation even under these conditions. The techniques described show how to design a system to given accuracy and response time. An equation is obtained for determining the necessary source strength as a function of the required response time and the gamma energy. In obtaining this equation, discussion is provided to help select the "proper" gamma energy. Since a wide variety of gamma source energies of long half-life and reasonable cost is not available, compromise is usually necessary. The discussion of streaming errors shows how this problem, as reported by others $[2,3,4]$, can be minimized. The general features of the density measurement system outlined allow it to be readily adapted to such measurements as: two-phase fluid density, or the density of flowing granular solids as in automated materials processing. For purpose of illustration, our discussion can be applied to the measurement of the density of a fluid or mixture flowing in a pipe. 


\section{THEORY}

\section{GENERAL}

Gamma rays passing close to and through atoms of material are occasionally scattered by interaction with the more tightly bound electrons of the atoms. Quantitative calculations of the attenuation of a beam of gammas passing through assemblies of atoms have been achieved by assigning to each type of atom a total gamma interaction cross section $\sigma$. For a given type of atom, $\sigma$ varies with the gamma energy and has units of $\mathrm{cm}^{2} /$ atom. In a region of density $\rho, \mathrm{g} / \mathrm{cm}^{3}$, the net interaction cross section per unit volume is then No $\rho$ where $\mathrm{N}$ is the number of atoms of the type in question per gram of the material. Because $\mathrm{N} \sigma \rho \mathrm{dx}$ represents a scattering cross-sectional area per unit beam area encountered by the beam in distance $\mathrm{dx}$, a gamma beam of intensity $\mathrm{I}$, gammas $/ \mathrm{cm}^{2} \mathrm{sec}$, will suffer gradual attenuation of gammas or original energy and direction, $\mathrm{dI}=-\mathrm{IN} \sigma \rho \mathrm{dx}$. Replacing $\mathrm{I}$ by $\mathrm{R} / \mathrm{A}$ where $\mathrm{A}$ is the cross-sectional beam area at the detector and $R$ is the number of gammas/sec, one has $\mathrm{AdR}=-\mathrm{ARN} \sigma \rho \mathrm{dx}$ or $\mathrm{dR}=-\mathrm{RN} \sigma \rho \mathrm{dx}$. Denoting $\mathrm{N} \sigma$ by constant, $\mathrm{k}$, (k being equal to $\mu / \rho$ of the litetature ${ }^{[5]}$ ) representative of the gamma energy and the material in question,

$$
\mathrm{R}=\mathrm{R}_{\mathrm{o}} \exp \left(-\mathrm{k} \int \rho \mathrm{d} \mathrm{x}\right)
$$

It should be remembered that a gamma-material interaction does not generally result in absorption of the gamma, but only deflection and some loss of energy. Thus, even though the scattered gammas are present, Equation (1) refers only to the rate, R, of gammas passing in the original direction still having the original energy.

If the total attenuation length is a constant, $\mathrm{x}_{\mathrm{O}}$, the product $\mathrm{k} \int \rho \mathrm{dx}$ can be replaced by $\mathrm{q} \rho$ eff with $\mathrm{q}=\mathrm{kx}_{\mathrm{o}}$ resulting in

$$
R=R_{0} \exp \left(-q \rho_{\text {eff }}\right)
$$

Use of the symbol $\rho_{\text {eff }}$ rather than $\rho$ calls attention to the fact that the density usually is not constant along the path of integration. Consideration of nonhomogeneity error is given in Section II-4.2.

Hooker and Popper ${ }^{[2]}$ utilize a less general version of the above equation. Assuming uniform distribution so that $\rho_{\text {eff }}=\rho_{\text {avg }}$ and denoting $a$ as the void fraction, for a two-phase mixture one has:

$$
\rho_{\text {eff }}=(1-\alpha) \rho_{1 i q}+\alpha \rho_{\text {vap }}=\rho_{1 i q}-\alpha\left(\rho_{1 i q}-\rho_{\text {vap }}\right)
$$

If temperature and pressure, $\mathrm{T}$ and $\mathrm{p}$, are fixed at some set of saturation values, $\rho_{\text {liq }}$ and $\rho_{\text {vap }}$ are each constant. Thus, under these constraints, Equation (2) can be written:

$$
R=R_{0}^{\prime} \exp \{+q \kappa \alpha\}
$$


where $\mathrm{R}_{\mathrm{O}}^{\prime}=\mathrm{R}_{\mathrm{O}} \exp \{-\mathrm{q} \rho$ liq $\}$ and $\kappa=\left(\rho_{\text {liq }}-\rho_{\text {vap }}\right)$. With $\mathrm{T}$ and $\mathrm{p}$ constant, Equation (4) shows that $R$ varies exponentially as a function of the void fraction. Naturally, if $T$ and $p$ vary (i.e., a new saturation temperature is selected) the "constants" $R_{o}^{\prime}$ and $\kappa$ vary. Thus, Equation (4) is of little usefulness if the saturation temperature and pressure are changing but Equation (2) remains valid.

\section{COLLIMATION AND/OR ENERGY ANALYZATION}

To use the relationship $\mathrm{R}=\mathrm{R}_{\mathrm{O}} \exp \left\{-\mathrm{q} \rho_{\text {eff }}\right\}$ directly without the need to worry about the intensity due to scattered, secondary gammas, either the energy of each gamma entering the detector must be ascertained before it is counted or secondary (scattered) gammas must be prevented from entering the detector. Since a gamma undergoes a change in direction when it is scattered, collimation of the gamma beam before and after the interaction region will serve to pass nearly all primaries and very few secondaries.

Large source strengths are required to achieve fast, accurate measurements since frequency response is related to beam intensity for a given statistical fluctuation. Because of : the high count rates thus encountered and because collimation enhances the ratio of primaries to secondaries reaching the detector, collimation is nearly always necessary even when energy analyzation is used.

In addition, if the material whose density is being measured is itself somewhat radioactive, utilizing collimation on the detector side of the measurement region serves the added purpose of enhancing the ratio of primaries to measurement-region radiation. In fact, it then becomes evident that it is best to place most of the collimation on the detector side of the measurement region.

The actual collimation required is a strong function of the situation. The very least that should be used is containment of the detector such that gammas can only reach it from the general direction of the source. An arrangement that has been found to be more than adequate by the author is to collimate to an extent such that no gammas can directly reach the detector from any portion of the measurement region that is more than 2.0 gamma beam diameters from the beam centerline.

\section{MEASUREMENT RESPONSE TIME}

The relationship between response time, measurement accuracy, and source strength is the subject of this section. Because the detector output originates from discrete gammas incident upon the detector tube, the calculation of response time attainable versus source size and desired accuracy regresscs naturally (even for dc current collection) to counting-statistics calculations. 
Since radioactive sources emit gammas in a random manner versus time, Poisson statistics are followed. Thus, for a measurement time $\tau$; and a mean count rate, $R$; the standard error, $\sigma$, in $R$ is $\sqrt{R / \tau}$. A deviation from $R$ of less than $K \sqrt{R / \tau}$ will be encountered in $\mathrm{f}(\mathrm{K}) \%$ of a series of measurements. Table $\mathrm{I}$ lists various values of $\mathrm{K}$ and the confidence level, $\mathrm{f}(\mathrm{K})$, with the commonly associated statistical title ${ }^{[6]}$.

Figure 1 illustrates the time variation of a typical dynamic density measurement where $R_{o}$ is the detector gamma detection rate for a completely empty measurement region and $R_{1}$ is the detector gamma detection rate for a "completely full" measurement region.

\section{TABLE I}

VALUES OF $f(K)$ VERSUS $K$

\begin{tabular}{ccl}
\hline$\frac{\mathrm{K}}{0.67}$ & $\frac{\mathrm{f}(\mathrm{K}), \%}{50.0}$ & $\frac{1}{\text { Title }}$ \\
1.00 & 68.3 & Probable Error \\
1.65 & 90.0 & $9 / 10$ Error \\
1.96 & 95.0 & $95 / 100$ Error, $2 \sigma$ \\
\hline
\end{tabular}

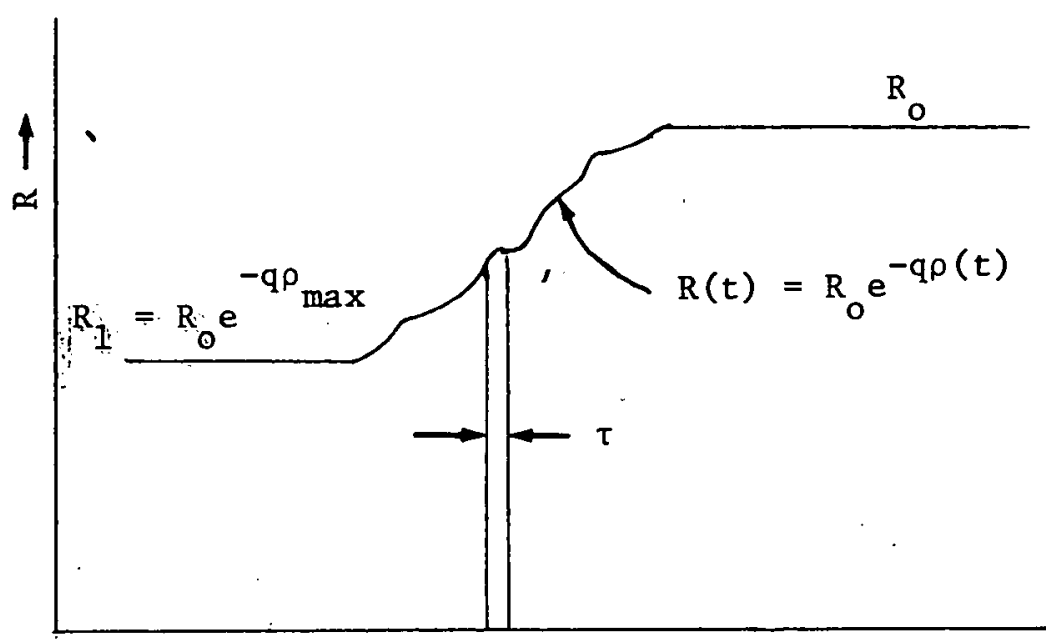

Fig. 1 Variation of $\mathrm{R}$ during typical dynamic density measurement. 
Thus, associated with $R(t)$ is a statistical error $\Delta R$,

$$
\Delta \mathrm{R}=\mathrm{K} \sigma=\mathrm{K} \sqrt{\mathrm{R}(\mathrm{t}) / \mathrm{l}}
$$

where $\mathrm{K}$ is selected from Table $\mathrm{I}$ by choosing the desired measurement level of confidence, $f(K)$. Since the value of $R$ varies from $R_{1}$ to $R_{0}$, the signal in terms of percent of full scale is:

$$
\% \text { of } \mathrm{FS}=100 \% \frac{\mathrm{R}(\mathrm{t})-\mathrm{R}_{1}}{\mathrm{R}_{0}-\mathrm{R}_{1}} \pm 100 \% \frac{\Delta \mathrm{R}}{\mathrm{R}_{0}-\mathrm{R}_{1}} \text {. }
$$

The first term on the right hand side of Equation (6) is the mean value of the measurement and the last term is the percent of full scale error associated with the measurement.

By substituting the expression for $\Delta \mathrm{R}$ from Equation (5) into the last term of Equation (6), an equation relating the percent of full scale error to the gamma detection rate, measurement time, $t$, and confidence level is obtained.

$$
\% \text { of FS error }=\frac{100 \times K \sqrt{R(t) / \tau}}{R_{0}-R_{1}} .
$$

If, for example, a $5 \%$ measurement with 0.9 confidence level (i.e., $K=1.645$ ) is desired, one has

$$
5=\frac{100 \times 1.645 \sqrt{R(t) / \tau}}{R_{0}-R_{1}} .
$$

This expression could then be solved for $R_{0}$ to determine the empty-measurement region count rate required to get the desired measurement accuracy for a given $\tau$ and $q \rho(t)$ product. Instead, the general expression in $\mathrm{K}$ and $\%$ error (i.e., $5 \%$ in the above example) is solved for $\mathrm{R}_{\mathrm{o}}$ in Equation ( 9 ) by using $\mathrm{R}_{1}=\mathrm{R}_{\mathrm{o}} \exp \{-\mathrm{q} \rho \max \}$ and $\mathrm{R}(\mathrm{t})=\mathrm{R}_{\mathrm{o}} \exp \{-\mathrm{q} \rho(\mathrm{t})\}$.

$$
R_{0}=\frac{\exp \{-q \rho(t)\}}{\tau}\left\{\frac{100 \mathrm{~K}}{\left(1-e^{-q \rho} \max \right)(\% \mathrm{FS} \text { error })}\right\}^{2}
$$

As noted previously, $R_{0}$ is the detector gamma detection rate for a completely empty measurement region. To get the actual source strength required one must multiply $R_{o}$ by: $\exp \{+q \rho(t)\}$, the measurement region attenuation; $\exp \left\{+\mathrm{k} \rho\right.$ met $\left.x_{\text {met }}\right\}$, the wall attenuation; the inverse of the detector efficiency, $1 / n$; the inverse of the source gamma yield, $1 / \gamma$; and the solid angle geometry factor $4 h^{2} / r^{2}$. The geometry factor originates from $4 \pi h^{2} / \pi r^{2}$ where the source is assumed to radiate gammas uniformly in all directions, $h$ is the distance from source to detector, and $r$ is the collimation radius at the most restrictive location (usually just in front of the detector as in Figure 2). Thus Equation (9) becomes:

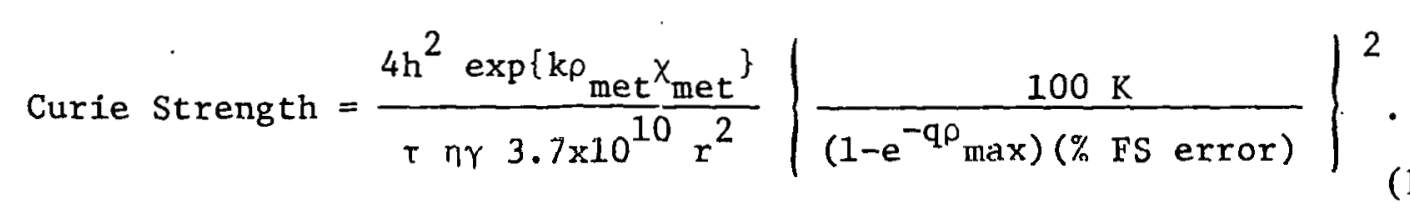




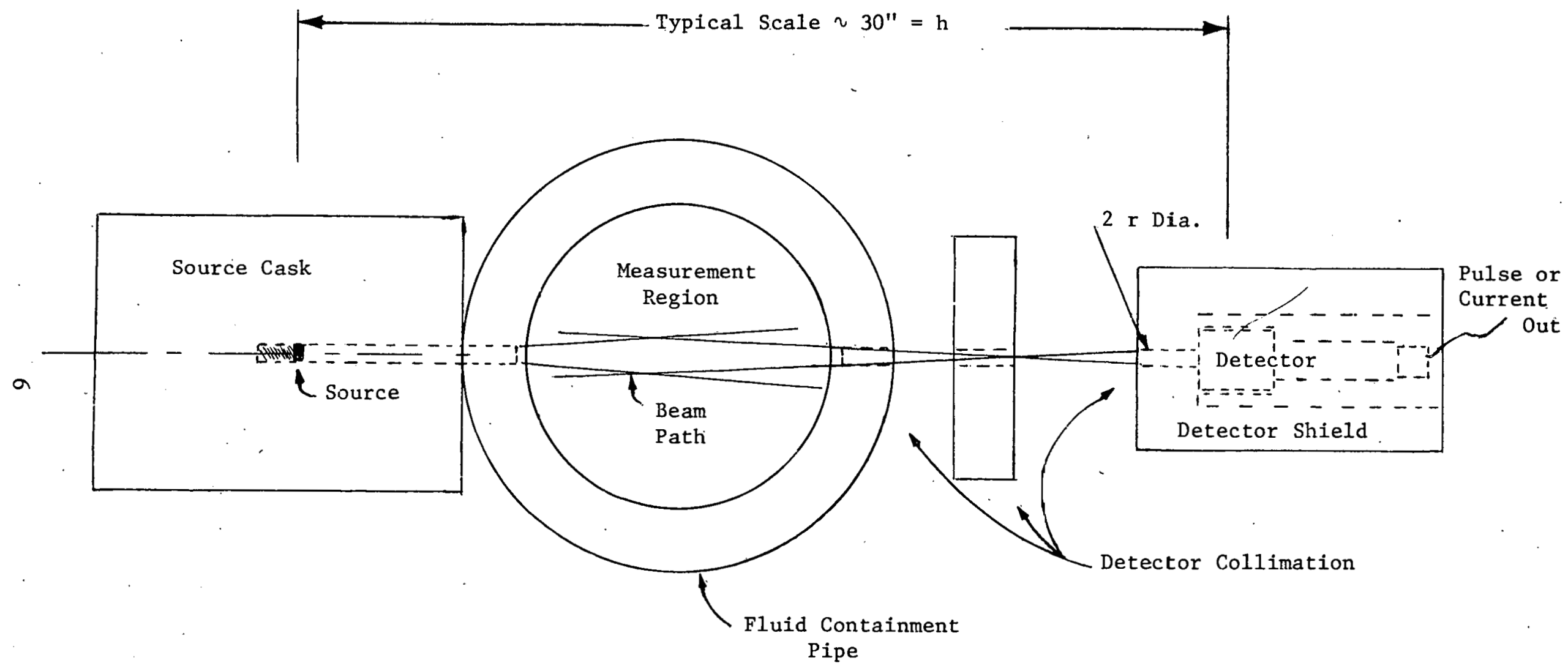

Fig. 2 Typical piping gamma attenuation density measurement 
Evans [7] shows that if a simple RC filter is used rather than counting for time $\tau$, the effective value of $\tau$ is $2 R C$. Since $f_{3 d B}=1 / 2 \pi R C^{[8]}$, one has $\tau=1 / \pi f_{3 d B}$ and the above equation becomes:

Curie strength $=\frac{4 \mathrm{~h}^{2} \pi \mathrm{f}_{3 \mathrm{~dB}} \exp \left\{\mathrm{k} \rho_{\text {met }} \chi_{\text {met }}\right\}}{\mathrm{n \gamma} 3.7 \times 10^{10} \mathrm{r}^{2}}\left\{\frac{100 \mathrm{~K}}{\left(1-\mathrm{e}^{-\mathrm{q} \rho} \max \right)(\% \text { FS error })}\right\}^{2}$

Because the last term in Equation (11) is squared, variation of any of the terms within requires large variations in the necessary source strength. The term $\left(1-\mathrm{e}^{-\mathrm{q} \rho} \max \right)$ is kept from being small by selecting a source with gamma energy such that filling the measurement region with the material whose density is to be measured causes significant decrease in detector output so that a measurement can be made. A value of $\mathrm{e}^{-\mathrm{q} \rho} \max$ less than 0.05 should be avoided, though, for two reasons. First, the large secondary to primary ratio requires extensive collimation at the detector to eliminate the secondaries. And, second, streaming becomes significant if nonhomogeneities are present (see Section II-4.2). Increasing the frequency response also, naturally, requires a larger source strength to maintain a given value of $\mathrm{K}$ and $\% \mathrm{FS}$ error. This effect is linear, though, rather than squared. Note, that for a given source strength, $3 \mathrm{~dB}$ frequency, and statistical uncertainty, the \%FS error is independent of the value of the measurement region density., $\rho(t)$.

\section{ERRORS}

\subsection{Logging and Data Bias}

For Poisson statistics, $\bar{R}$ is located midway between the $\pm K \sqrt{R(t) / \tau}$ statistical error bands. If one utilizes the natural $\log$ function to transform Equation (2) to the density domain, the question arises whether or not $\bar{\rho}$ is somewhere near centered within the transformed error bands.

$$
\bar{\rho}=-\frac{1}{q} \ln \left(\frac{\bar{R}}{R_{0}}\right)
$$

If for $\mathrm{R}=\overline{\mathrm{R}}+\Delta \mathrm{R}$ the indicated $\rho$ is $\bar{\rho}-\Delta \rho_{1}$ and for $\mathrm{R}=\overline{\mathrm{R}}-\Delta \mathrm{R}$ the indicated $\rho$ is $\bar{\rho}+\Delta \rho_{2}$, one can write:

$$
\bar{\rho}-\Delta \rho_{1}=-\frac{1}{\mathrm{q}} \ln \left(\frac{\overline{\mathrm{R}}+\Delta \mathrm{R}}{\mathrm{R}_{\mathrm{o}}}\right)
$$

and

$$
\bar{\rho}+\Delta \dot{\rho}_{2}=-\frac{1}{q} \ln \left(\frac{\bar{R}-\Delta R}{R_{0}}\right) .
$$


Using Equation (12) for $\bar{\rho}$ and $\Delta \mathrm{R}=\mathrm{K} \sigma$ in each of the above equations gives, after some simple algebra:

$$
\Delta \rho_{1}=+\frac{1}{q} \ln \left(1+\frac{K \sigma}{\bar{R}}\right)
$$

and

$$
\Delta \rho_{2}=-\frac{1}{q} \cdot \ln \left(1-\frac{K \sigma}{\bar{R}}\right) \text {. }
$$

Because, by Equation (7), one can infer that for a statistically meaningful measurement that $\overline{\mathrm{R}}>\mathrm{K} \sigma$, a good approximation of Equations (15) and (16) is $\Delta \rho_{1}=\Delta \rho_{2}=\mathrm{K} \sigma / \mathrm{q} \overline{\mathrm{R}}$. Thus, in the region of interest where the statistical error is not large, the mean value of density is equal distance from the transformed statistical error bounds. Filtering could then be performed either before or after logging without significant data bias, but is more correctly performed in a stage prior to logging. In a situation where $\Delta \mathrm{R}$ (due to changing density in the measurement region rather than to statistics) can be oscillatory and significant compared to $\overline{\mathrm{R}}$, noticeable error in the indicated versus the actual $\bar{\rho}$ will be experienced if filtering is performed after logging rather than before.

\subsection{Gamma "Streaming" or Nonhomogeneity Error}

Picture a gamma beam directed along the $\mathrm{k}$ axis passing through the measurement region as shown in Figure 3. If there are two phases of the same material in the measurement region, the mixture can be conceptually broken into smaller regions which are either one phase or the other. Summation of portions of the beam passing through each small region then will yield the exiting beam intensity. Equation (17), showing the form of this summation, makes use of the fact that q's for each phase of a material are equal. The sum over $\mathrm{k}$, in the argument of the exponential is simply an approximation to the line integral of Equation (1) for column $i, j$. The double sum over $i$ and $j$ in front of the exponential adds the fluxes from each of the $i, j$ columns.

$$
R=\frac{R_{0}}{m n} \sum_{i=1}^{m} \sum_{j=1}^{n} \exp \left\{-\frac{q}{r} \sum_{k=1}^{r} \rho i j k\right\}
$$

Although the space in the near proximity to the beam is usually referred to as the measurement region, density sensing actually only occurs in the small volume "swept out" by the gamma beam. The remainder of this section will be used to show that the transverse extent of the gamma beam should be limited to minimize "streaming". Section II-4.3 shows, though, that a single such measurement, although accurate for the "beam volume", can be in error with respect to the total measurement region density because of nonuniform distribution of the fluid and container geometry. 


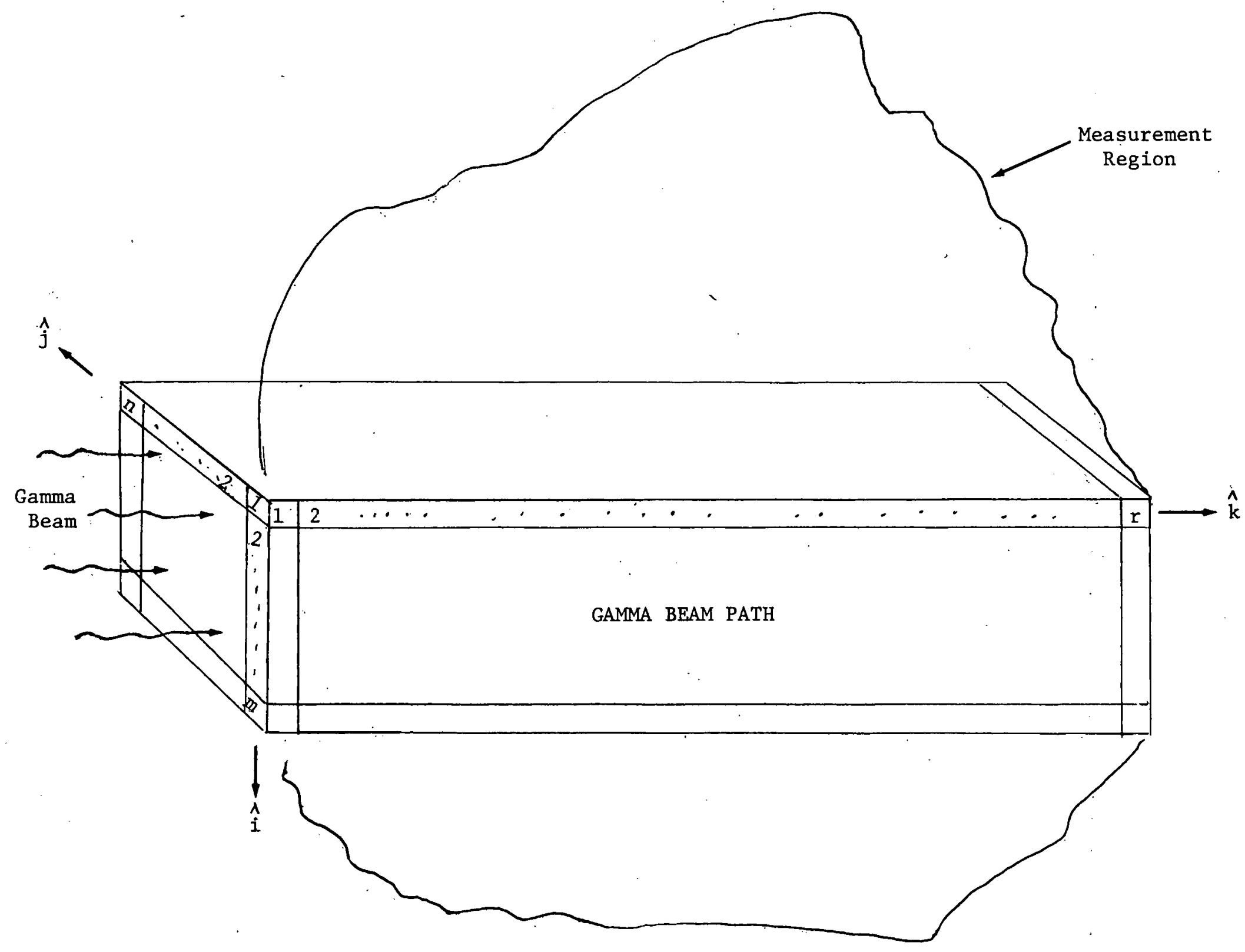

Fig. 3 Splitting of the gamma beam path into parts. 
For a given $\mathrm{i}$ and $\mathrm{j}$, the summation $\frac{1}{\mathrm{r}} \cdot \sum_{\mathrm{k}=1}^{\mathrm{r}} \rho_{\mathrm{ijk}}$ is the average density, $\rho \mathrm{ij}$ avg, of the $\mathrm{i}, \mathrm{j}$ column, so:

$$
R_{\text {out }}=\frac{R_{o}}{m n} \quad \sum_{i=1}^{m} \sum_{j=1}^{n} \exp \left\{-q \rho i j j_{\text {avg }}\right\} .
$$

Now if every column has the same value, $\rho_{\mathrm{avg}}$, for $\rho \mathrm{ij}_{\mathrm{avg}}$, one has:

$$
\rho_{\text {avg }}=\frac{1}{m n r} \sum_{i=1}^{m} \sum_{j=1}^{n} \sum_{k=1}^{r} \rho i j k
$$

and

$$
R_{a v g}=\frac{R_{o}}{m n} \quad \sum_{i=1}^{m} \sum_{j=1}^{n} \exp \left\{-q \rho i j_{a v g}\right\}=R_{o} \exp \{-q \rho a v g\}
$$

In the case of "laminar" flow (two phases separated into laminar planes perpendicular to the gamma beam) and in the case of completely homogeneous flow (the two phases finely and uniformly mixed), $\rho \mathrm{ij}_{\mathrm{avg}}=\rho_{\mathrm{avg}}$ for all $\mathrm{i}$ and $\mathrm{j}$. Thus, in these two cases, at least, $\mathrm{R}=$ $\mathrm{R}_{\mathrm{o}} \mathrm{e}^{-\mathrm{q} \rho}$ avg. We also see that if lamina (thin compared to the beam width) are oriented parallel to the beam, $\frac{1}{\mathrm{r}} \sum_{\mathrm{k}=1}^{\mathrm{r}} \rho_{\mathrm{ijk}}=\rho \mathrm{ij}$ avg has very small value for those $\mathrm{i}, \mathrm{j}$ located in the low density lamina and slightly above $\rho_{\text {avg }}$ value for the $i, j$ not located in the low density lamina. "Streaming" is then said to occur in this low density lamina because gamma attenuation in the low density lamina region is very low. To show that too large a net output occurs for this material phase configuration we form the ratio $R_{\text {out }} / R_{\text {avg }}$ and find it greater than unity.

$$
\left.\frac{R_{\text {out }}}{R_{\text {avg }}}=\frac{1}{m n} \sum_{i=1}^{m} \sum_{j=1}^{n}\left(e^{+q[\rho} a^{-\rho i j}{ }_{a v g}\right]\right)
$$

Since the quantity $\mathrm{q} \mid \rho$ avg $-\rho \mathrm{ij}_{\text {avg }} \mathrm{l}$ is not large we can expand the exponential $\mathrm{e}^{\mathrm{X}}=1+\mathrm{x}+$ $\frac{x^{2}}{2}+\cdots$

Because $\sum_{\mathrm{i}=1}^{\mathrm{m}} \sum_{\mathrm{j}=1}^{\mathrm{n}} \mathrm{q}\left(\rho_{\mathrm{avg}}-\rho \mathrm{ij}_{\mathrm{avg}}\right)=0$, one gets to $\mathrm{x}^{2}$ approximation that:

$$
\frac{R_{\text {out }}}{R_{\text {avg }}}=1+\frac{1}{2 m n} \sum_{i=1}^{m} \sum_{j=1}^{n}\left\{q\left[\rho_{\text {avg }}-\rho i j{ }_{\text {avg }}\right]\right\}^{2} \text {. }
$$


Thus, since the sum of squared terms must be greater than or equal to zero, $R_{\text {out }} / R_{\text {avg }}$ is greater than or equal to unity. Because $\rho$ is determined from the output, $R_{\text {out }}$, by $(1 / q) \ln \left(R_{o} / R_{\text {out }}\right), \rho_{\text {out }}$ will be less than (or equal) to the actual average density of the material in the gamma beam path. As mentioned just after Equation (11), use of a higher energy gamma has a smaller value of $q$ so the additional term in Equation (22) is reduced in value. Too high an energy gamma, though, leads to insensitivity and to a need for large source strength as indicated by Equation (11) when $\mathrm{e}^{-\mathrm{q} \rho \max }$ is close to unity.

In summary, the streaming error occurs whenever the width of the gamma beam is not small compared to the width of those "fluid" lamina oriented parallel to the beam. Use of a narrow gamma beam and higher energy gammas helps to decrease the streaming. The narrower beam decreases the number of terms in the sum of Equation (22), and the higher energy gamma decreases the value of $q$.

\subsection{Wall Adherence Error (Annular Flow)}

When a medium physically separates into two phases, as it often does, the meaning of the attenuated gamma output becomes subject to interpretation. If, for instance, homogeneous mixed flow in a circular pipe of inside diameter, $\mathrm{d}_{\mathrm{O}}$, s̈eparates into central flow with diameter $\mathrm{d}_{1}$ of density $\rho_{1}$ and annular flow of density $\rho_{\mathrm{O}}$, the average density is:

$$
\rho_{\text {avg }}=\frac{\rho_{1} d_{1}^{2}+\rho_{0}\left(d_{0}^{2}-d_{1}^{2}\right)}{d_{0}^{2}}
$$

But the gamma attenuated output is

$$
R_{\text {out }}=R_{0} e^{-k d_{0}\left[\rho_{1} \frac{d_{1}}{d_{0}}+\rho_{a}\left(1-\frac{d_{1}}{d_{0}}\right)\right]}
$$

whereas the output needed to predict the density of Equation (23) would be

$$
R_{\text {avg }}=R_{0} e^{-k d} 0\left\{\rho_{1}\left[\frac{d_{0}}{d_{0}}\right]^{2}+\rho_{0}\left(1-\left[\frac{d_{1}}{d_{0}}\right]^{2}\right)\right\}
$$

The ratio $R_{\text {out }} / R_{\text {avg }}$ is an indication of the magnitude of the output error:

$$
\frac{\mathrm{R}_{\text {out }}}{\mathrm{R}_{\text {avg }}}=\mathrm{e}^{+\mathrm{kd} \mathrm{d}_{1}\left(\rho_{\mathrm{o}}-\rho_{1}\right)\left(1-\frac{\mathrm{d}_{1}}{\mathrm{~d}_{0}}\right)} \cdot
$$

Since the density $\rho_{\mathrm{o}}$ of the annular phase is normally larger than $\rho_{1}, \mathrm{R}_{\text {out }}$ is greater than it should be. The predicted density is, therefore, less than it should be. Since $d_{1}$ is usually not known, use of a single gamma measurement does not allow accurate evaluation of $\rho_{\text {avg }}$. 
Where the flow regime is such that the model of ideal annular flow of density $\rho_{0}$ with central flow of density $\rho_{1}$ is accurate, use of two gamma measurements of distinctly different gamma energies (with attenuation constants $k$ and $k^{\prime}$ ) allows measurement of $d_{1}$. Since $R_{\text {out }}$ in this case behaves as Equation (24):

$$
R_{\text {out }}=R_{0} e^{-k d_{0}\left[\rho \frac{d_{1}}{1 d_{0}}-\rho_{0}\left(1-\frac{d_{1}}{d_{0}}\right)\right]}
$$

and for gammas of the other energy:

$$
R_{\text {out }}^{\prime}=R_{0}^{\prime} e^{-k^{\prime} d_{0}}\left\{\rho_{1} \frac{d_{1}}{d_{0}}-\rho_{0}\left(1-\frac{d_{1}}{d_{0}}\right)\right\} \text {. }
$$

Solving these for $\mathrm{d}_{1}$ :

$$
d_{1}=d_{0}\left\{\frac{\ln \left(\frac{R_{\text {out }}^{\prime}}{R_{\text {out }}} \frac{R_{o}}{R_{o}}\right)}{\rho_{o}(k-k)}\right\}
$$

For a true two-phase fluid $\rho_{0}$ and $\rho_{1}$ are the liquid and vapor densities at the saturation pressure for the instant in question. Assuming the primes to be used for the higher energy gamma ( $k-k^{\prime}$ ) will be positive. Assuming further that $R_{o}=R_{o}{ }^{\prime}, R_{o u t}^{\prime}$ will be greater than $R_{\text {out }}$. The total $\log$ term is then positive. Thus, Equation (29) consists of division of differences between numbers that are of similar size, and care must be taken in measuring $\mathrm{R}_{\text {out }}^{\prime}$ and $\mathrm{R}_{\text {out }}$ to get meaningful answers. Problems such as flow separation due to gravity, etc., may require use of three or more gamma measurements at different energies, angles, etc., to obtain sufficient information to interpret outputs with confidence.

To determine mass flow in a pipe of cross-sectional area $\mathrm{A}$, the problem is more complicated than just measuring density because each of the two separate phases generally have different mean velocities, $\bar{v}_{0}$ and $\bar{v}_{1}$. For the present case of separated annular flow:

$$
\text { Mass F1ow }=(\rho \mathrm{vA})_{\text {avg }}=\frac{\pi}{4}\left\{\rho_{0} \bar{v}_{0} d_{0}^{2}-d_{1}^{2}\left(\rho_{0} \bar{v}_{0}-\rho_{1} \bar{v}_{1}\right)\right\} \text {. }
$$

But neither $\bar{v}_{0}$ nor $\bar{v}_{1}$ are generally known. If flow is indeed separated as assumed, pitot tubes can be used in each of the two regions to obtain the velocities, but pitot tubes will not yield correct answers in mixed flow. 


\subsection{Scintillator and Photomultiplier Related Errors}

A scintillator coupled to the photocathode of an electron multiplieris one of the most efficient gamma-ray detectors in the $60 \mathrm{keV}$ to $3 \mathrm{MeV}$ gamma-ray energy range of interest. A common scintillator is a crystal of sodium iodide activated by a small percentage of thallium. The sensitivity of this gamma sensing system is influenced by the various factors considered below. Although these factors are not important when counting techniques are used, if the output current of the photomultiplier is used for the value of $R_{\text {out }}$, all of the effects below affect the value of $R_{\text {out }}$ (and $R_{o}$ ).

4.41 Scintillator Crystal Temperature Sensitivity. For constant gamma stimulation, the output current from a $\mathrm{NaI}$ (T1) Scintillator electron multiplier tube rises about $0.07 \% /{ }^{\circ} \mathrm{F}$ temperature rise when operated near room temperature. Because one eventually logs $R_{\text {out }}$ to obtain $\rho_{\text {avg }}$, only the ratio of the current to some reference current $R_{O}$ is important. Thus, unless the empty measurement region output, $\mathrm{R}_{\mathrm{O}}$, can be frequently measured, the drift in $R_{o}$ leads to all ratios being formed with an incorrect reference. Containing the photoscintillator in a fixed temperature container will of course eliminate the problem.

4.42 Electron Multiplier Voltage Sensitivity. The electron multiplier ${ }^{[9]}$ current gain is very sensitive to changes in dynode resistor chain drive voltage. Typical change in current gain per volt change in the total (900 volt nominal) chain voltage is $0.6 \% /$ volt. A well-regulated power supply placed in a temperature-stabilized environment is suggested. The effect of dynode drive voltage change is the same as changes in photoscintillator sensitivity discussed above. Temperature stable resistors (derated considerably from manufacturers suggested power rating) are necessary in order that the dynode resistor chain not vary the voltage dynode to dynode versus time or temperature for a fixed total chain voltage.

4.43 Electron Multiplier Space Charge Sensitivity. As the electron current increases at dynodes farther away from the photocathode, the charge in the space about a dynode increases. If the net current in the final stage of the multiplier reaches a value above about one microampere (depending on dynode width, size, drive voltage, etc.), mutual repulsion forces between electrons causes output to increase in a slightly nonlinearly manor with photocathode input rate. Various options are available to prevent this:

If a high count rate is required to minimize statistical fluctuation (see Section II-3), current (or pulses) can be withdrawn from a dynode upstream of the regular collection dynode. When using counting techniques at high counting rate, the upstream dynode collection technique has the additional advantage of decreasing the spread in arrival time of the electrons originating from a given gamma stimulus.

If the high count rate is needed to minimize statistical fluctuations and the space charge effect in only very slightly evident, the dynode resistor chain voltage may 
be decreased a few volts. Too low a chain voltage, though, will cause nonconstant current gain and even complete loss of some pulses. This leads to excessive statistical fluctuation.

4.44 Electron Multiplier Dynode Activation Memory Error. With dynode current density at say $10^{-6}$ ampere $/ \mathrm{cm}^{2}$, each and every dynode surface atom site is impacted every 100 seconds. With every 100 surface atom sites being stimulated once per second, the dynode suffers a change in its secondary emission "constant" from its value at lower dynode current density. In effect, the microarea remembers that it has recently been impacted and its secondary emission response is slightly greater than if it had not recently been impacted. Thus, if the gamma stimulation rate is suddenly decreased a factor like 10, the photomultiplier output also suddenly decreases a factor of len bul then continuos to decrease very slightly for a period of time until the memory effect adjusts to the new dynode current density. For low dynode current density, the electron impingement rate is not sufficient for the memory effect to develop. The solution as in Subsections II-4.42 and -4.43 is to remove the current from the electron multiplier at a stage (before the regular collector dynode) where the dynode current is luw enough that the memory effect is not noticeable. An output current of $10^{-8}$ amperes has been found to be low enough to make the memory effect nearly undetectable.

\subsection{Electronics Errors}

If the current from the electron multiplier is used as $R_{\text {out }}$ and is run into a current-logging amplifier, drift in the logging amplifier ordinarily will change the full scale voltage output change per full scale change in density and both the "full" and "empty" output voltages. Thus, if current logging electronics are used, it must be designed to be as drift free as possible. The heart of a current logging amplifier is usually a transistor in the feedback loop of an operational amplifier. For stable results, a temperature controlled (Peltier cooled) dual logging transistor used with the two transistors in the feedback loops of two operational amplifiers has been found to work well. The two operational amplifiers then drive a differential operational output amplifier. Although temperature compensation techniques might be used rather than absolute temperature control on the logging transistor temperature, the transistor's behavior versus temperature is different at one current than at another. Commercial, temperature-compensated logging circuits and compensation curcuits built by the author were all found to be unsatisfactory.

If the current or the raw counts/sec data are linearly recorded and operated on by digital computer to take the $\log$ of $\mathrm{R}$ to determine $\rho$, the current-logging amplifier and its drift are eliminated. 


\section{CONCLUSIONS}

A gamma attenuation density measurement using a well-collimated, narrow beam of gammas of proper primary energy allows accurate determination of the total mass of material in the beam path.

The source curie strength necessary to obtain a given response time and percent statistical uncertainty (to a given confidence level) is readily calculated for a given geometry, full-range density change, and gamma energy.

Data bias due to filtering can be prevented by filtering prior to logging of $R_{\text {out }}$.

Gamma streaming is minimized by using a narrow gamma measurement beam of adequate primary energy.

Nonhomogeneous arrangements of two-phase "fluids" in the measurement region force one to use two or more gamma measurements at different angles, and/or gamma energies in order that a meaningful fluid configuration and density value be interpreted from the outputs.

In addition to the above considerations, to obtain accurate results, proper use and understanding of the gamma detection system are important. 


\section{REFERENCES}

1. E. O. Doebelin, Measurement Systems: Application and Design, McGraw-Hill Book Company Inc., New York (1966), p 488.

2. H. H. Hooker and G. F. Popper, "A Gamma-Ray Attenuation Method for Void Fraction Determinations in Experimental Boiling Heat. Transfer Test Facilities", ANL-5766 (1958).

3. V. E. Schrock, "Radiation Attenuation Techniques in Two-Phase Flow Measurements", in Two-Phase Flow Instrumentation (11th National ASME/AIChE Heat Transfer Conf., August 1969), p 24.

4. M. Petrick and B. S. Swanson, "Radiation Attenuation Method of Measuring Density of a Two-Phase Fluid", Rev. Sci. Instr. 29, 1079 (1958).

5. H. Etherington, Nuclear Engineering Handbook, McGraw-Hill Book Company, Inc., New York (1958) p 7-62.

6. W. J. Price, Nuclcar Radiation Detection, McGraw-Hill Book Company, Inc., New York (1958), p 58.

7. R. D. Evans, The Atomic Nucleus, McGraw-Hill Book Company, Inc., New York (1955), p 804.

8. R. G. Brown and J. W. Nilsson, Introduction to Linear Systems Analysis, John Wiley and Sons, Inc., New York (1962), p 125.

9. W. J. Price, Nuclear Radiatton Detection, McGraw-Hill Bonk Company, Inc., New York (1958), p 174. 
